\title{
Comprehensive ArcGIS-Based Urban Drainage Modeling for Decision Support
}

\author{
Trent Schade, Paul Boulos, Chris Baxter and \\ Misgana Muleta,
}

Computer simulation models of urban drainage systems represent the most effective and viable means for evaluating system response to various management strategies. To be effective, these models require extensive spatial utility infrastructure data readily available from a Geographic Information System (GIS). Indeed, a utility's database contains the objects that make up the network and information about these objects. The GIS is used to link this information to the digital map. Used as a spatial database, GIS can greatly assist in various modeling and analysis applications through the development of automated tools for constructing and maintaining reliable network models of urban drainage systems. This chapter presents a comprehensive GIS-based decision support system that integrates several technologies for use in the effective management of urban stormwater collection systems. It explicitly integrates ESRI ArcGIS geospatial model with advanced hydrologic, hydraulic, and water quality simulation algorithms based on the USEPA SWMM5 urban drainage network solver, global optimization techniques based on fast messy genetic algorithms for calibration and design, automated dry weather flow generation and allocation, and automated subcatchment delineation and parameter extraction to address every facet of urban drainage infrastructure management.

Schade, T., P. Boulos, C.W. Baxter and M. Muleta. 2007. "Comprehensive ArcGIS-Based Urban Drainage Modeling for Decision Support." Journal of Water Management Modeling R227-14. doi: 10.14796/JWMM.R227-14

(C) CHI 2007 www.chijournal.org ISSN: 2292-6062 (Formerly in Contemporary Modeling of Urban Water Systems. ISBN: 0-9736716-3-7) 
Comprehensive modeling of sewer collection systems is essential to develop reliable and cost-effective remedial solutions for enhancing system integrity and performance, restoring and maintaining needed capacity, avoiding backups and overflows and meeting environmental regulations to improve public health and safety. However, modeling of urban stormwater and sewer collection systems requires extensive spatial and temporal data due to the complexity of the governing processes and the heterogeneity of watershed properties and flow paths and conduits found in developed and undeveloped urban areas. These features are geographic in nature and suggest the need for an efficient spatial data management and analysis tool such as a GIS. A GIS is both a database system with specific capabilities for spatially referenced data, as well as a set of operations for working with the data (Poku and Arditi, 2006). It provides functions for development and preparation of accurate spatial information for input (pre-processing) to urban drainage system models. It also facilitates post-processing spatial analysis and graphical output display for evaluating results. Therefore, the marriage of mathematical stormwater models and GIS ensures that sound engineering solutions are drawn efficiently and effectively in the planning, design, operation, and maintenance of wastewater collection systems (Miles and Ho, 1999). These benefits are being realized by wastewater utilities and municipalities in managing their sanitary, storm and combined sewer system infrastructures.

Shamsi (2002) distinguishes three different methods to link a GIS to simulation (mathematical) models: interchange, interface, and integration, listed in order of complexity and versatility. The interchange method employs a batch process to transfer data between the GIS and simulation model. Both GIS and the simulation model are run separately and no direct link exists between the two systems. The interface method provides a direct link to exchange information between the GIS and the simulation model with customized pre- and post-processing functions added to the GIS. However, the interface method also requires the simulation model to run independently from the GIS. The integration method represents the closest relationship between the GIS and the simulation model. The method combines both the GIS and the modeling functions in one complete seamlessly integrated package. It provides the basis for a comprehensive decision support system for the effective management of urban drainage systems.

In addition to ensuring seamless integration of GIS with a mathematical model that simulates the hydrology, hydraulics and water quality of urban drainage systems, a comprehensive decision support model should have: 
tools that facilitate watershed delineation and extraction of input parameters from digital topographic, soil and land use data; a calibration model that adjusts parameter values so that model predictions closely match observed data; a design model that determines cost-effective solutions to eliminate flooding and associated pollution problems; a load allocation tool that computes wastewater loads entering the collection system at various locations; and the capability to analyze important water quality parameters whose improper management could cause serious problems including loss of life (Nicklow et al., 2004, 2006).

This chapter presents an integration of the USEPA storm water management model (SWMM5) for hydrologic, hydraulic, and water quality simulation with GIS (ArcGIS, ESRI, Redlands, California) and an efficient variation of genetic algorithms (GA) optimization technology to address every facet of urban wastewater management activities. The resulting integrated system effortlessly reads GIS data, extracts necessary modeling information such as subcatchment parameters, and automatically constructs, loads, calibrates, designs, analyzes and optimizes a representative model considering hydraulic, water quality and hydrologic management and operational requirements. It also makes it easy to simulate various scenarios, identify deficiencies, and determine cost-effective improvements for optimum performance. It is a single software platform that addresses the requirements of both wastewater utility engineers and GIS professionals and provides an informative structured framework for complete sewer model construction, analysis, optimization, and results presentation. These combined capabilities provide a consistent geospatial environment to assist wastewater utilities in planning, designing, and operating reliable systems, evaluating the effectiveness of best management practices (BMPs), and in optimizing their capital improvement programs. The benefits of the proposed decision support system are illustrated by application to an example stormwater collection system and conclusions are stated.

\subsection{Methodology}

Social choice processes help determine a fair way to accomplish something for the common good; they are voting algorithms. Multi-objective choice systems adapt the social choice processes to more complex decisions. These systems attempt to provide fair decision making through layers of objective ranking and solution ranking. For multiple objectives and multiple solutions, 
these methods become quite complex and time consuming to implement. The systems to implement these may include evaluation tools, model state information and process information. This type of tools provides invaluable information for the evaluation of design options, keeping in mind that the design evaluation can only be as good as the subset of designs evaluated (Dym et al., 2002; Dym and Little, 2000).

The following sections describe the foundations of good decision support systems and describe two key technologies (geospatial data analysis and advanced optimization) that, when implemented together, will revolutionize decision support systems for future water resource decision making.

\subsubsection{Decision Support Systems}

Decision Support Systems (DSS) as defined by Reitsma et al. (1996) include three elements of the system's architecture: (i) state information, (ii) process information, and (iii) evaluation tools. From this rather limited definition and in the context of decision-making, the DSS describes the current state of a system, the physical behavior of a system, and tools to help evaluate system behavior under different adaptations. The DSS achieves this by creating layers of information about a system and processing that information according to laws or rules like physics, economics or policy in order to evaluate environmental impacts, societal acceptance or fiscal costs. Ostensibly, the DSS provides a great deal more than merely a system architecture for alternative evaluations, yet additional structure to problem solving is often necessary (Reitsma, 1996). For example, a DSS applied to water resources problems on the Colorado River provides a framework for discussion and evaluation, but the system itself cannot generate alternatives. The stakeholders involved have to insert alternatives which leads to some debate (Reitsma, 1996). Figure 14.1 shows a schematic of a DSS for multiple criteria.

The clear benefits of the DSS are twofold. First, the stakeholders acknowledge their own interests in the process prior to generating alternative solutions. This means that the stakeholders are not interested, indebted or wed to a particular solution, and they can approach alternatives with openness. Having elucidated their needs and having those needs recorded in the process information portion of the decision support system allows them to feel like their voice was heard in the process.

Secondly, experts in urban water modeling from outside of the stakeholder group objectively provide the analytical framework. While stakeholder interests determine the constraints, these independent experts 
provide the data and analytical models. The architecture of a Decision Support System can eliminate rancorous and technical discussions among project stakeholders about minute technical details. Theoretically, it provides unbiased, clear consistent results for each alternative, leaving the stakeholders free to objectively evaluate alternatives.

No social choice system is perfect. With this DSS model, the system relies on stakeholders to generate alternatives, leaving the process open to bias by "stocking" illegitimate or ill-conceived alternatives that may still meet system constraints. In these cases, the political element involved in the decision process usually eliminates any "bad actors" in the process.
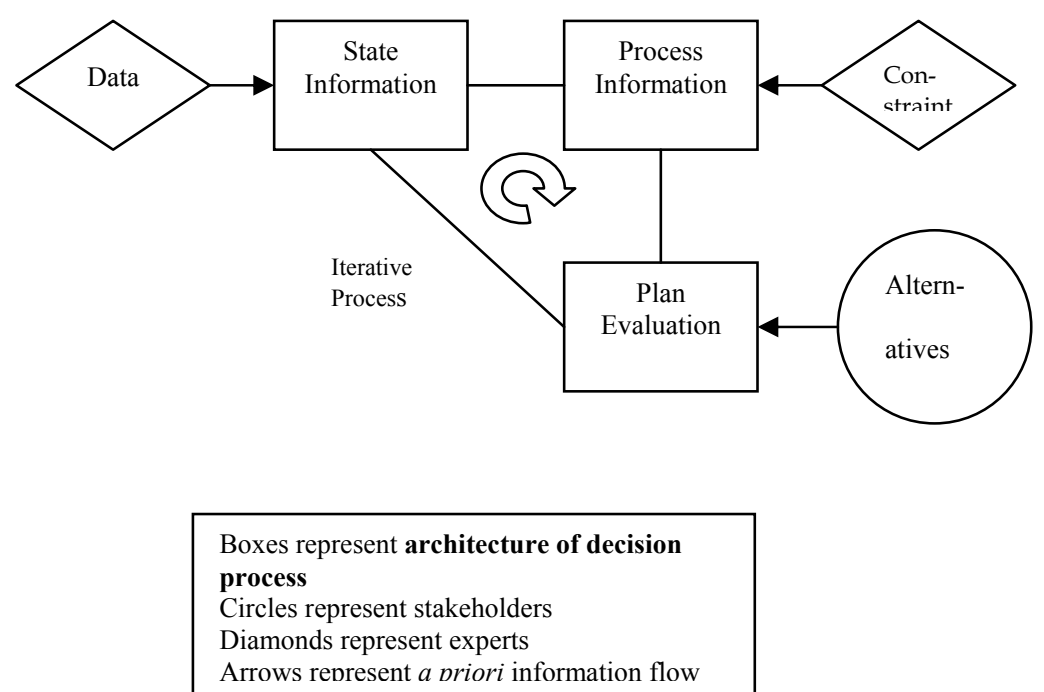

Figure 14.1 DSS schematic.

\subsubsection{A Geospatial DSS}

The proposed decision support system approaches wastewater collection system modeling from a GIS-centric point of view and works to minimize the efforts needed to create, analyze and optimize a drainage system model. As shown in Figure 14.2, the core of the geospatial decision support system 
is the central geodatabase for storage, manipulation, and display of the collective simulation model results. No data conversion is required and the user interacts directly with the GIS (there is no need to exit the GIS to edit data or run an analysis). The geospatial user interface initializes the GIS environment, creates all the necessary input files, builds network topology, sets hydrologic, hydraulic and water quality parameters and optimization constraints, runs and compares any number of modeling scenarios, and displays and tabulates results.

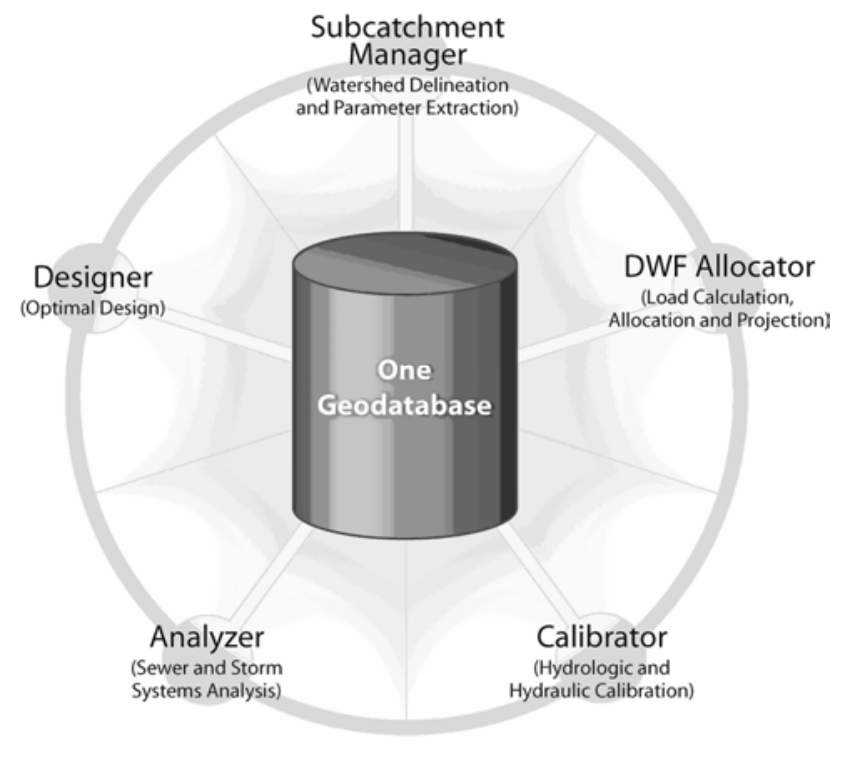

Figure 14.2 The GIS-centric decision support model architecture.

\subsubsection{Optimized Geospatial DSS}

The proposed GIS-centric DSS hosts, in a unifying framework, the variety of processes required for loading, calibrating, analyzing, and optimizing wastewater collection network models. These are divided into five embedded simulation modules for automated dry weather flow (DWF) estimation and allocation (DWF Allocator); subcatchment parameter extraction (Subcatchment Manager); hydrologic, hydraulic and water quality analysis (Analyzer); optimal calibration (Calibrator); and least-cost design 
(Designer). It combines the ability to accurately build network topology, prepare requisite data, conceive and evaluate multiple scenarios, execute optimization runs, and provide both hardcopy reporting and graphical output display for evaluating and presenting results.

The optimization modules are predicated on the use of the fast messy genetic algorithm (fmGA), which is one of the most competent types of GA delivering reliable solutions in sub-quadratic time (Boulos et al, 2003). They operate jointly with the hydrologic, hydraulic and water quality solver (simulation module) to provide direct feedback on impacts of computed solutions on wastewater collection system performance. Both modules are applied in a convergent scheme as follows. The optimization model initially creates a population of candidate solutions, which are then passed to the network solver to analyze the hydrologic, hydraulic and water quality performance in satisfying the imposed constraints. The computed solutions are then passed to the decision support system for use in quantifying the objective function and any constraint violations. This information is then used to produce a new population with better-fit members which is then passed back to the network solver for subsequent evaluation. The iteration continues until a specified level of convergence is reached. Because the decision support software was built using an open-system architecture approach, it can be easily expanded to incorporate additional simulation and optimization modules planned in the future.

Each module of the geospatial decision support system is described below.

\section{Drainage System Simulation Model (Analyzer)}

The Analyzer modules uses the EPA SWMM5 (Rossman, 2005) model to solve urban drainage hydrology, hydraulics and water quality. It can model the entire land phase of the hydrologic cycle as applied to urban stormwater and wastewater collection systems. The model can perform single event or long-term (continuous) rainfall-runoff simulations accounting for climate, soil, land use, and topographic conditions of the watershed. In addition to runoff quantity, it can simulate runoff quality including buildup and washoff of pollutants from primarily urban watersheds. Once runoff quantity and quality is simulated and wastewater loads at receiving junctions are determined, the routing portion transports the flow using steady, kinematic wave or dynamic wave routing, through a conveyance system of pipes, channels, storage/treatment devices, pumps, and hydraulic regulators such as weirs, orifices, and other outlet types. It can accurately simulate complex 
flow conditions including backwater effect, flow reversal, and pressurized flow. Because it couples together the solution for both water levels at nodes and flow in conduits, Analyzer can be applied to any general network layout, even those containing multiple downstream diversions and loops. The model offers advanced Real-Time Control (RTC) scheme for the operational management of hydraulic structures.

\section{Subcatchment Parameters Extractor (Subcatchment Manager)}

Proper delineation of watersheds is critical for accurate stormwater modeling applications. The Subcatchment Manager (Figure 14.3) provides a suite of geospatial tools for defining watershed data in a GIS and then using the information to directly create and manage hydrologic and hydraulic models, or as a support utility for data development from topographic, soil, and land use maps. To simulate runoff quantity, the Analyzer module requires subcatchment inputs including area, imperviousness, slope, width (a shape factor), and infiltration parameters for Horton, the Green-Ampt, or the Curve Number methods for individual subcatchments in the system. The Subcatchment Manager is designed to utilize digital topographic data such as DEM, TIN, contours, and point elevation to delineate watersheds, streams/channels, and subwatersheds, and to extract the hydrologic parameters listed above for each subcatchment from topographic, land use, and soil maps available for the watershed.

Using the Subcatchment Manager, one can quickly delineate a watershed for an urban drainage system; subdivide the watershed into subwatersheds (or subcatchments); create streams (channels) and converts these channels into conduits of any shape; create an outlet for the drainage system; create rainfall time series from radar data; assign raingauge to subcatchments based on their geographic proximity; determine subcatchment parameters such as width (using several methods), area, and slope from DEM, TIN, contours or point elevations; extract percent imperviousness and subcatchment land use types from digital land use data; determine infiltration parameters from digital soil map, and develop depth versus area curve for detention ponds from DEMs. In other words, with the help of Subcatchment Manager alone one can build a working urban drainage system model from topographic, land use, soil, and radar data. The model enables water resources engineers to devote more time understanding problems and evaluating sound solutions instead of performing drudgery. 


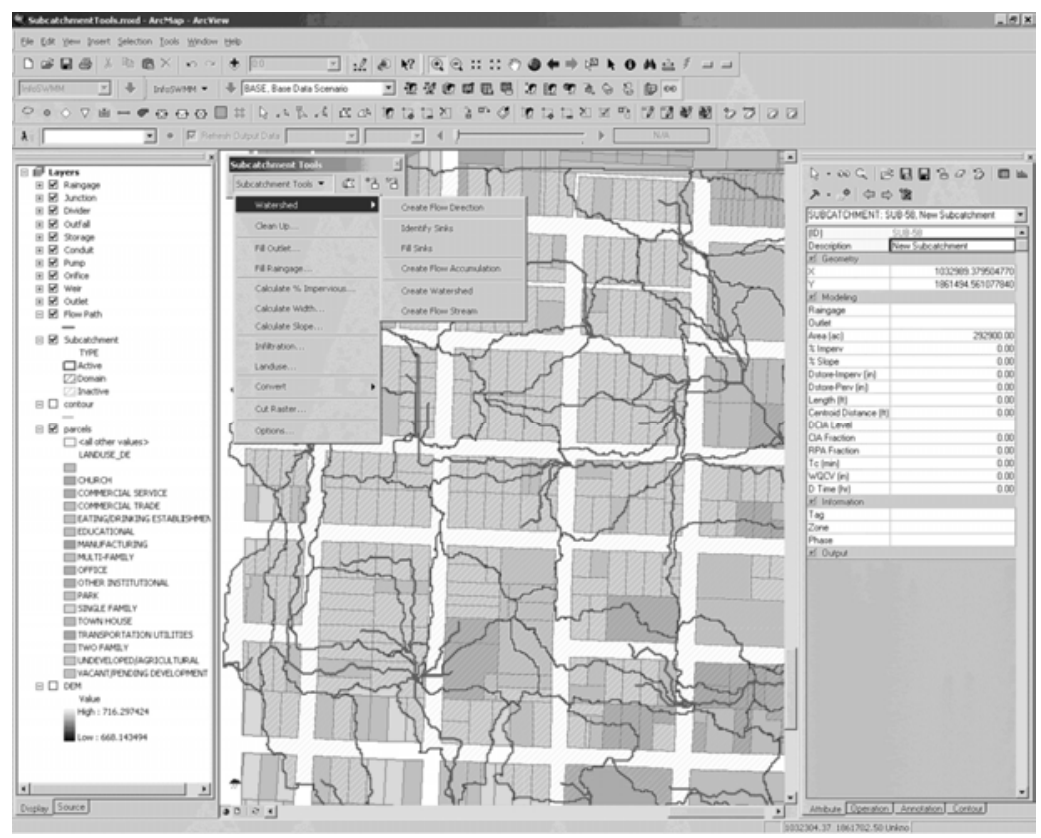

Figure 14.3 The GIS-centric Subcatchment Manager module.

\section{DWF Load Estimation and Allocation (DWF Allocator)}

Determining wastewater loads and their spatial distribution throughout the drainage system model is a key element of wastewater collection system modeling. DWF data can be derived from many sources including flow metering, water consumption records, system flows, and estimates from consumer characteristics, such as population, land use, traffic counts, or other parameters. These data are assigned as DWF values at individual junctions within the collection system model where selected junctions receive flows from distinct service areas. Generally, the average DWF loads are first estimated for all junction nodes, and temporal (e.g., diurnal and seasonal variation) of the loads are then adjusted for various land use categories such as residential and commercial areas. The DWF Allocator module is designed to assist in the process of generating and allocating network DWF loads for existing system conditions and for various planning horizons. It offers seven methods for processing geometric polygons to compute and load network models based on load type, location, and variation (Figure 14.4). These are: 
1. Geocoded meter billing data (meter DWF database),

2. Polygon intersection - spatial intersection of multiple polygon layers,

3. Polygon extraction - spatial summation of DWF category area polygons,

4. Closest Junction - allocate loads to the nearest junction,

5. Closest Conduit - allocate loads to the nearest conduits,

6. Meter-Junction Allocation - user-defined assignment of meters to junctions, and

7. Meter-Conduit Allocation - user-defined assignment of meters to conduits.

The first method uses GIS layers to allocate geocoded load data. Here, the DWF Allocator determines the flow at each network junction by identifying and summing all the customers/meters in its associated load area polygon. These loads include customers such as residential, commercial, industrial, schools, parks, golf courses, hospitals, etc. which are drawn directly from their spatially located water consumption records. In the second method, the DWF Allocator calculates flows based on direct spatial intersection between load categorization polygons (e.g., land use polygons, population polygons, pressure zone polygons, TAZ polygons, census tract polygons, meter route polygons, and others) and load area coverage polygons (service area polygons). In the third method, junction flows are calculated by summing individually assigned load category polygons. The fourth and the fifth methods work in conjunction with geocoded customer/meter data. The fourth method locates the junction closest to the meter by using advanced search algorithms and then allocates loads. In the fifth method, search algorithms are used to locate the closest conduit to each meter. Loads are then assigned to the nearest junction on either side of the conduit or divided based on a distance-weighted approach. The last two methods are similar to the closest conduit and the closest junction methods, except the user is able to determine which meters will be assigned to which junctions and conduits in the system. The meter-junction and the meterconduit allocation methods allow the user the freedom to graphically determine which meters are tributary to which junctions and conduits in the sewer collection system.

These comprehensive capabilities give practicing engineers considerable flexibility to effectively utilize their knowledge and experience and leverage existing GIS data investments to strategically define/forecast their network DWF load estimation for various planning horizons in their master planning effort. 


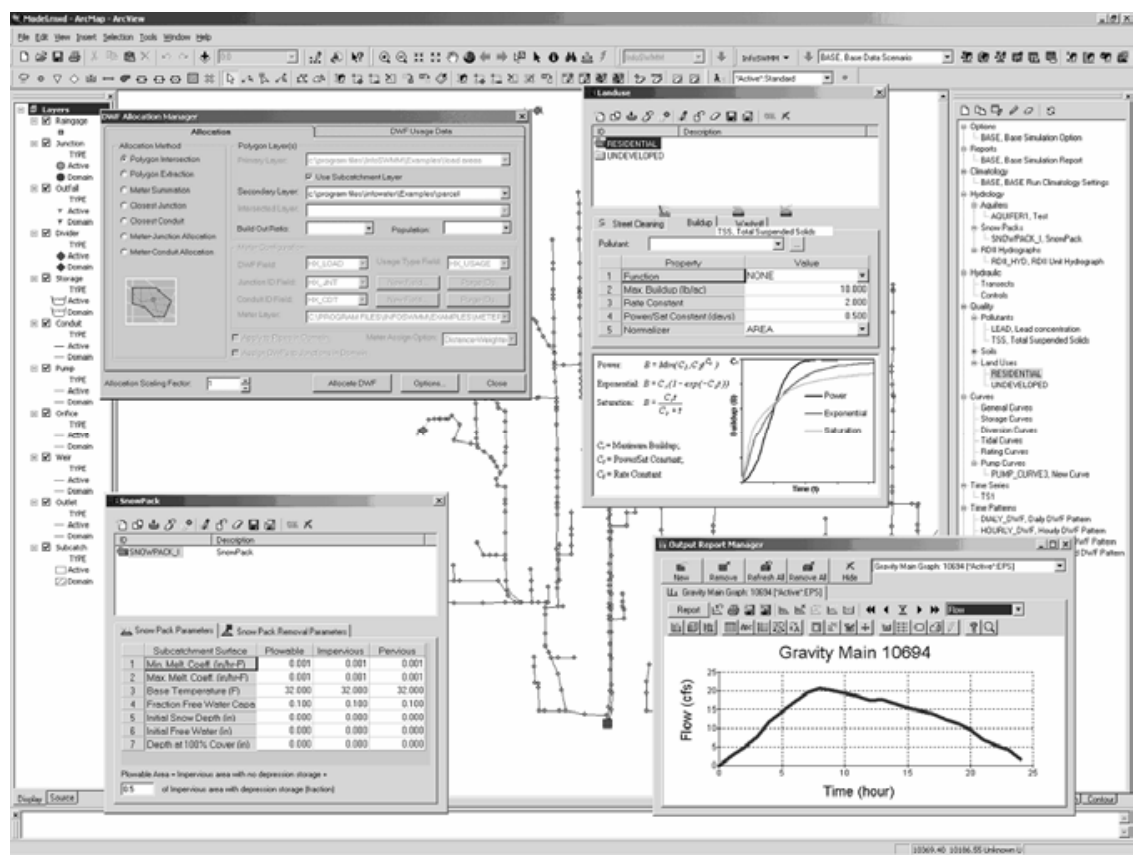

Figure 14.4 The GIS-centric DWF load allocation module.

\section{Network Model Calibration (Calibrator)}

After a network model is properly constructed, it must be calibrated to the physical system so that model predictions can be interpreted with confidence (Muleta and Nicklow, 2005). Traditionally, calibration of an urban drainage network model was an exhaustive trial-and-error process of adjusting the model input parameters until model results coincide with field observations. However, since there is a vast number of combinations of parameter values that need to be considered, manual evaluation of all options through trialand-error is unlikely to be practically feasible or manageable, and even knowledgeable modelers often fail to obtain good results. As a result, model calibration has generally been neglected or done haphazardly. The Calibrator (Figure 14.5) module fully automates and simplifies this manual process, making urban drainage model calibration significantly easier and the model more reliable. 


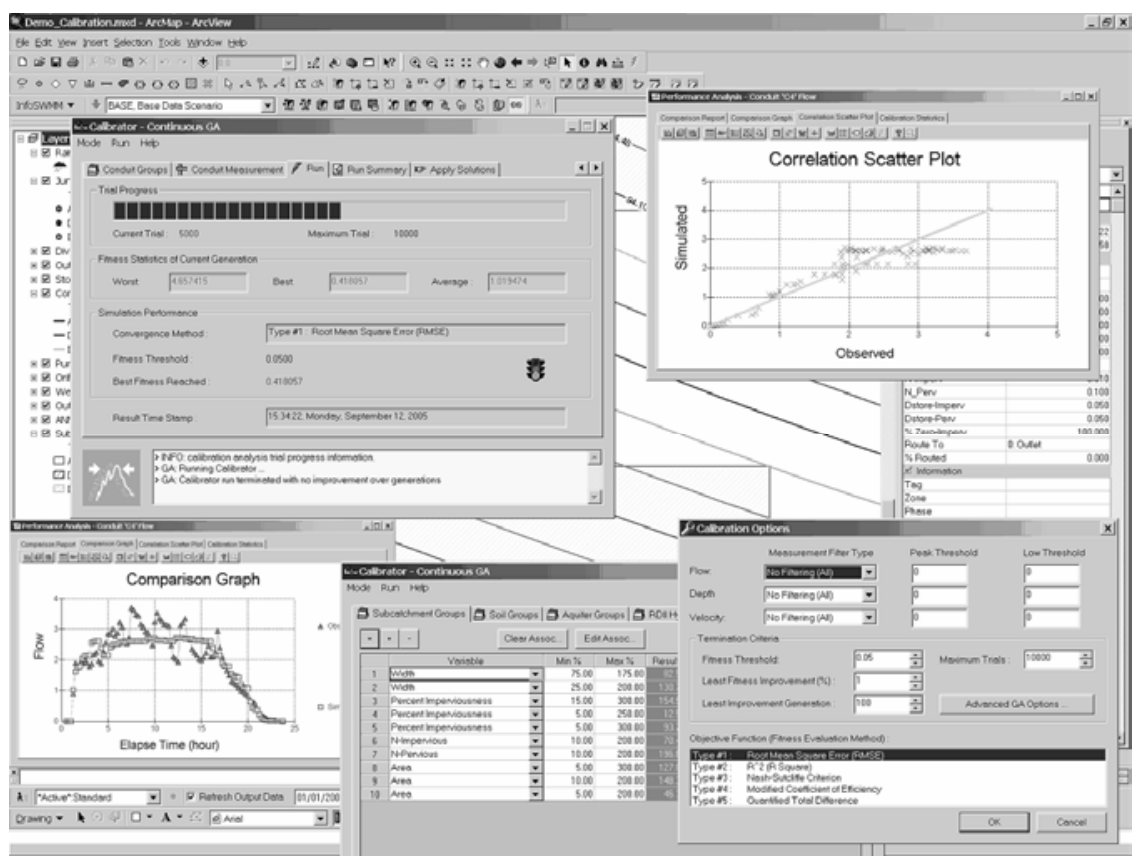

Figure 14.5 The GIS-centric optimal calibration module.

In order to improve the reliability of network models as well as eliminate the need for trial-and-error calibration methods, the calibration problem is cast as optimization problem and solved using the fast messy GA (fmGA) algorithm. Any combination of flow, depth, and/or velocity measurements could be used as observation, and the decision parameters are classified into five distinct groups (subcatchment group, soil group, aquifer group, RDII group, and conduit group). The subcatchment group represents subcatchment parameters and groundwater parameters including area, width, percent imperviousness, slope, Manning's $\mathrm{N}$ for pervious and impervious subareas, depression storage for pervious and impervious subareas, Colorado Urban Hydrograph Procedure parameters such as length, centroid distance, CIA fraction, RPA fraction, lag time for Natural Resources Conservation Service's dimensionless and triangular unit hydrograph method, groundwater flow coefficient, surface water flow coefficient, groundwater flow exponent, surface water flow exponent, surface-groundwater interaction coefficient). The soil group contains infiltration parameters 
including Horton's parameters such as maximum infiltration rate, minimum infiltration rate, decay rate, drying time, maximum volume; Green-Ampt parameters such as suction, conductivity, initial deficit and Curve Number parameters such as curve number, conductivity, and drying time. The aquifer group comprises aquifer parameters including porosity, wilting point, field capacity, conductivity, conductivity slope, tension slope, upper evaporation fraction, lower evaporation depth, bottom elevation, water table elevation, and unsaturated zone moisture. The RDII (Rainfall Driven Infiltration and Inflow) group represents RDII unit hydrograph parameters including $\mathrm{R}, \mathrm{T}$, and $\mathrm{K}$ for short-term, medium-term, and long-term responses, and the conduit group represents conduit parameters including the Manning's roughness coefficient.

The Calibrator module casts the calibration problem as an implicit nonlinear optimization problem, subject to explicit inequality and equality constraints. It computes optimal model parameters within user-specified bounds, such that the deviation between the model predictions and field measurements is minimized. The optimal model calibration problem is thus governed by an objective function and its associated set of constraints.

The objective function can be described using the root mean square error, simple least square error, mean simple least square error, Nash-Sutcliffe efficiency criterion, modified coefficient of efficiency, R-square, or the deviation in total volume of observed and simulated values. Any one of these evaluation criteria could be used to identify set of model parameters so that model simulations best fit the entire time series of the measured data, or peak values such as peak flows (measured values higher than specified threshold), or low values such as low flows (values lower than specified threshold).

The implicit constraints on the system correspond to equations that govern/simulate the underlying hydrologic, hydraulic and water quality processes including conservation of mass and conservation of momentum at various scales such as node, and/or link, and/or the entire system. Each function call to the Analyzer (SWMM5) with a set of decision variables returns the simulated values for link flow, link depth, and link velocity that will be compared with corresponding measured data.

The explicit bound constraints are used to set minimum (lower) and maximum (upper) limits on the decision variables.

Stopping criteria could be any one or more of fitness threshold (e.g., RSquare greater than 0.99), tolerance of the differences between observed and simulated values, the maximum number of model simulations, and improvement in the fitness criteria within specified number of generations. 
Calibration results are presented graphically (scatter plot and time series plot), in tabular form, and in the form of statistical summary.

Network Design (Designer)

Cost-effective design of urban drainage systems is one of the most pressing problems in engineering practice. Mitigation of the adverse impacts of flooding and the associated pollution problems is normally achieved using engineering measures such as placement of stormwater detention ponds, improving conveyance capacity by pipe upsizing, boosting pumping capacity, and by adding various combined sewer overflow (CSO) structures to the collection system. The objective is to minimize system improvement costs while satisfying regional environmental regulations for runoff quantity and quality control. The Designer module (Figure 14.6) solves the design problem using genetic algorithm optimization.

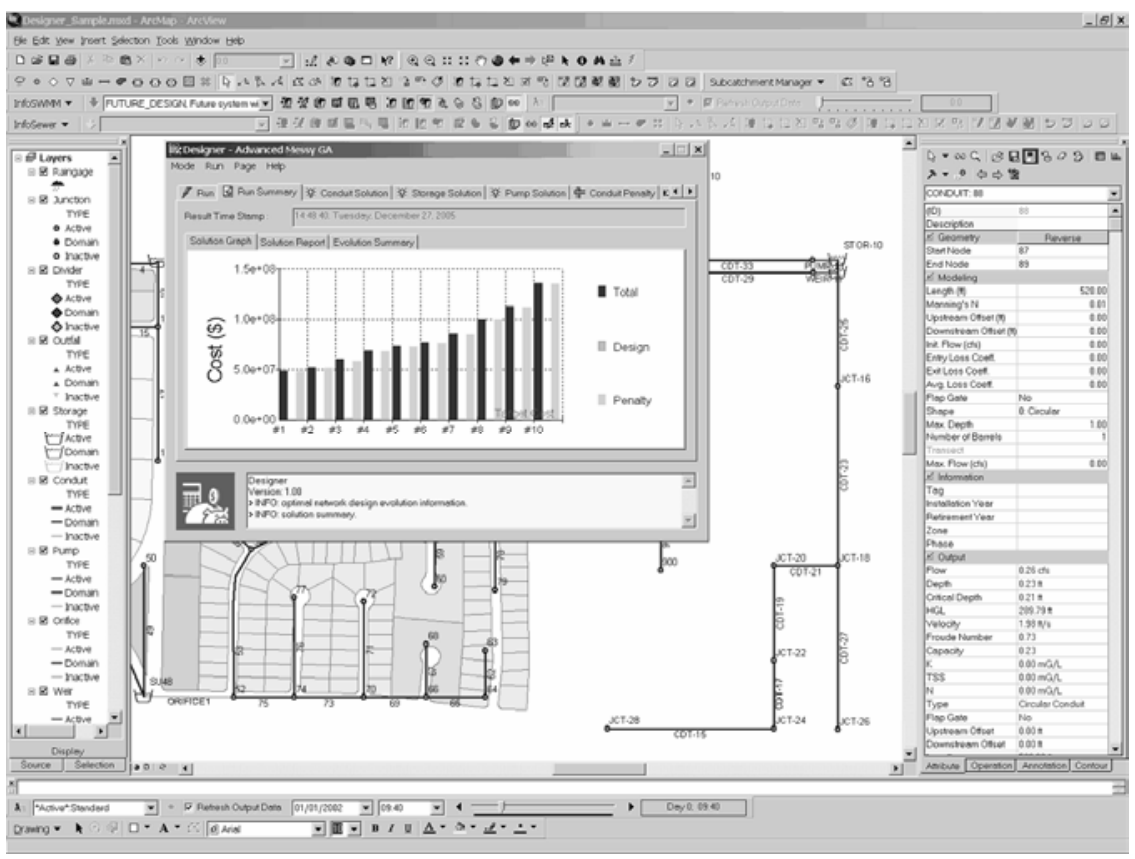

Figure 14.6 The GIS-centric optimal design module. 
The design problem is cast as an optimization problem and solved using the fmGA. The optimal solution is selected from a combination of pipe slope and size, storage, pumping, and new piping to eliminate unwanted sewer overflows and achieve targeted system performance requirements. Performance criteria include maximum allowable depth to diameter ratio, minimum and maximum pipe velocities and slopes, and maximum head loss for force mains. Cost data is specified for each option depending, for example, on the size and location the conduit, size and location of detention pond, and size and type of pump. Cost data could vary with geographical location of the network element. Results include top ten design solutions and associated costs presented graphically and in tabular form along with statistical summary. A detailed description of the optimal design module can be found in Boulos et al. (2006).

\subsection{Application}

\subsubsection{Study Area}

The study area described below is meant to represent a typical residential area with commercial development possibilities. Though mostly residential, this area is bracketed by two commercial developments. The stormwater drains in this area to the northeast where there is a drainage swale that eventually leads to a conduit beneath an interstate highway. Complicating matters further, the stormwater runoff from this area eventually reaches a stream subject to recent changes in a Total Maximum Daily Load calculation and has some interest from a watershed stakeholder group to limit the bed load of sediments in the stream.

As it currently stands, the area occasionally experiences street flooding that extends into the roadways bounding the property on the north and west causing a nuisance to neighbors and a traffic safety hazard. With the potential economic interests in redeveloping the land, there is significant opportunity to improve the drainage characteristics of the site to eliminate some of these existing issues.

\subsubsection{Stakeholder Interests}

The study area includes four stakeholder groups: the land development company (property owner), a watershed group, the state department of 
transportation (DOT), and the downstream property owners. The land development company is interested in developing the entire area into a commercial property. Other interests surrounding the land development will come into play, but this is the group with some interest in the stormwater management of the redeveloped property, and thus the focus of our interest. Table 14.1 summarizes the interests of each stakeholder group.

\subsubsection{Apriori Information}

Apriori Information includes two categories, available data and constraints. The available data includes the factual representation of the state of the system. This includes the physical aspects of the system that are verifiable and surveyable. Often this data is publicly available either for free or with a minimal cost. The geodatabase plays host to this type of data. The constraint information is gathered from the stakeholders prior to the evaluation of alternatives. This information can range from the subjective and qualitative to the objective and quantitative depending on the source's level of expertise and process understanding. With constraint information, it is sometimes necessary to interpret this information to place it into the correct context and format to reap the benefits of the DSS. The following sections describe the utilization of the DSS to collect archive and analyze both the available data and the system constraints.

Table 14.1 Stakeholder interests.

\begin{tabular}{lll}
\hline \multicolumn{1}{c}{ Stakeholder } & & \multicolumn{1}{c}{ Interests } \\
\hline Land Development Company & $\bullet$ & Meet legal requirements \\
& - & Minimize capital cost \\
Watershed Group & - Water quality concerns \\
DOT & Hydraulic Impacts \\
Adjacent Property Owners & - & Modifications to culvert beneath interstate \\
& & Attractive building/landscape \\
\hline
\end{tabular}

\section{Available Data}

The land development company performed preliminary engineering studies related to the feasibility of the proposed commercial property. As part of this study, the company collected the GIS data (shown in Table 14.2) and monitored pre-development flows. 
Table 14.2 GIS data.

\begin{tabular}{ll}
\hline \multicolumn{1}{c}{ GIS Data } & \multicolumn{1}{c}{ Source } \\
\hline Surface Elevation Data & National Database \\
Network Connectivity & Survey \\
Parcel Information & County GIS \\
Land-use and Zoning & Local Economic Development Council \\
Orthophoto & Private Land/Satellite Company \\
Soils Data & National Database \\
\hline
\end{tabular}

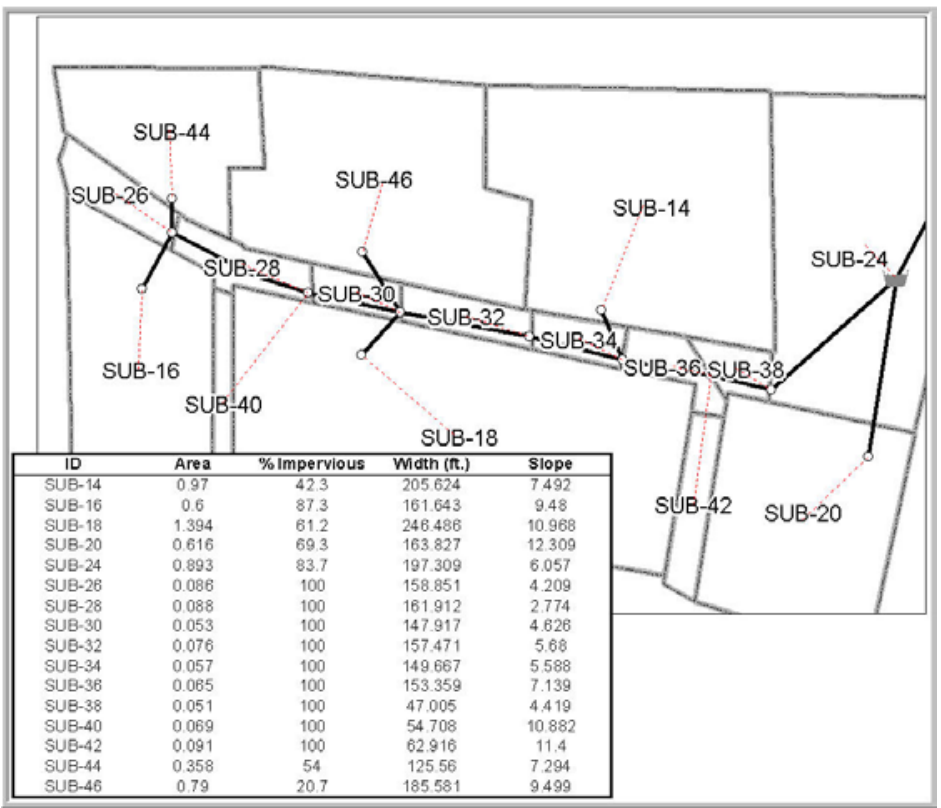

Figure 14.7 Network topology and subcatchment parameters.

Utilizing mostly data from public sources effectively supports an open ideal for stakeholder interest. This type of data is rarely disputed among stakeholders and, since it is stored in the GIS system, stakeholders are free to interact with the data (through the consultant) as needed.

Three components of the GIS-centric DSS utilize this data to perform some preliminary analysis in preparation for evaluating alternatives. The Analyzer module was employed to generate the network topology. Within the Analyzer, we can evaluate the survey by performing checks on the 
network connectivity including cross-connections, missing nodes, duplicate nodes and parallel conduits. The next step was to determine watershed parameters for each hydrological unit. The Subcatchment Manager was used to perform this task. Figure 14.7 shows the network topology including some of the key subcatchment parameters.

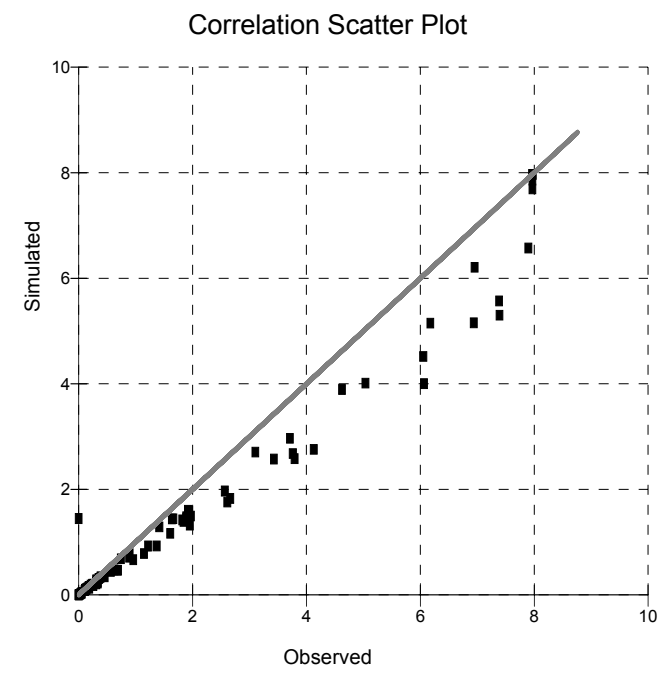

Figure 14.8 Calibration results.

With the network topology and subcatchment parameters in the stormwater model, we are able now to run the software. We picked a rainfall event that the consultant monitored flow at the outfall conduit and where some street flooding was observed. Utilizing depth and flow data at the outfall conduit, we built a calibration run in the hydraulic model. The results of this calibration run are a set of optimized network and subcatchment parameters that meet the criterion for a "calibrated" model. In this case, the criterion employed was to meet a root mean squared error (RMSE) between the observed and simulated values for flows where we filter out low flows ( $>3 \mathrm{cfs} ;>85$ lps). Figure 14.8 depicts the results of this calibration exercise.

\section{Constraints}

Before the consultant can begin to evaluate alternatives with a DSS, they must build into the DSS the constraints expressed by the stakeholders. Section 14.2.2 describes each stakeholder and their interests. The Designer 
module allows the user to quickly and efficiently implement all of these stakeholder interests in our criteria and constraints for a valid design. Figure 14.9 shows sections of the Designer dialog where we implement each constraint representing interests from each stakeholder.

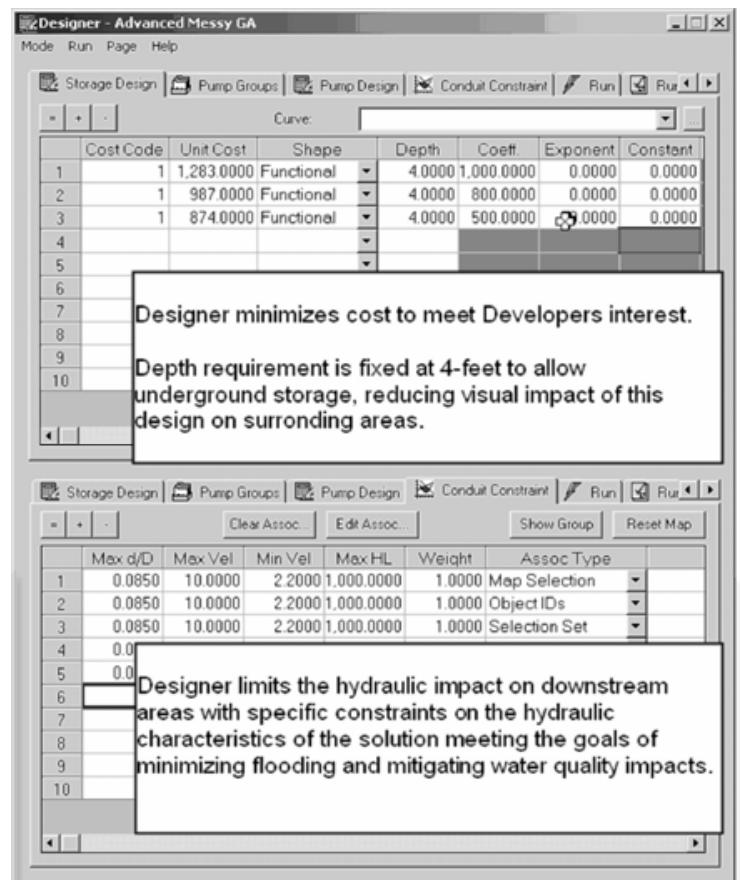

Figure 14.9 Designer implementation.

\subsubsection{Alternatives}

Using the Designer module, evaluating alternatives is a very simple task. Once we have all of the constraints established for the system, we simply select appropriate optimization options and launch the simulation. Designer runs through thousands of alternatives and finds the optimum solution in an expeditious manner. In this case, Designer selected to implement an underground 1,000 square foot (93 square meters) storage tank with a gravity outflow that will meet all of the project constraints. 


\subsection{Conclusions}

Today's wastewater utilities are discovering a wide variety of application areas of GIS technology. In particular, GIS information is critical to urban drainage system planning and analysis. A GIS-centric decision support system has been presented for use in comprehensive sewer collection system management. Built entirely atop of ArcGIS, the software seamlessly integrates GIS features and functionalities with sewer collection system hydraulic, hydrologic, and water quality simulation and genetic algorithmbased optimization technology. The integrated system allows accurate urban drainage network model construction and simulation, and provides a reliable and effective means for decision makers to quickly assess and address the implications of alternative design and operational changes on system performance. As the current trend towards the creation of comprehensive geodatabases continues, the proposed decision support system would be even more useful for planning and managing sewer collection systems. It allows a wide range of cost-effective network alternatives to be modeled, analyzed, contrasted, and evaluated, providing sound guidance to wastewater utility managers to effectively optimize their capital improvement programs, keep their systems operating well in the future, and forge closer ties with their customers. It is managing complexity through simplicity.

\section{References}

Boulos, P.F., et al. (2001). "Using genetic algorithms for water distribution system optimization." In Proceedings of the ASCE Environmental and Water Resources Institute's (EWRI's) World Water \& Environmental Resource Congress, May 20-24, Orlando, FL.

Boulos, P., T. Schade, C.W. Baxter and M. Muleta. 2006. "Optimal Design of Urban Drainage Systems using Genetic Algorithms." Journal of Water Management Modeling R227-11. doi: 10.14796/JWMM.R227-11.

Dym, C.L. and Little, P. (2000). "Engineering Design: A Project-Based Introduction." John Wiley \& Sons, Inc., New Yor, NY, 278 pp.

Dym, C.L., Wood, W.H., and Scott, M.J. (2002). "Rank ordering engineering designs: pairwise comparison charts and borda counts." Research in Engineering Design, 13, pp. 236-242. 
Miles, S.B., and Ho, C.L. (1999). "Applications and issues of GIS as a tool for civil engineering modeling." Journal of Computing in Civil Engineering ASCE, 13(3), pp. 144-152.

Muleta, M.K., and Nicklow, J.W. (2005). "Sensitivity and uncertainty analysis coupled with automatic calibration for a distributed watershed model." Journal of Hydrology, Elsevier, 306, pp. 127-145.

Nicklow, J.W., Boulos, P.F., and Muleta, M.K. (2004). "Comprehensive Sewer Collection Systems Analysis Handbook for Engineers and Planners." 1st ed., MWH Soft Publ., Pasadena, CA, 273 pp.

Nicklow, J.W., Boulos, P.F., and Muleta, M.K. (2006). "Comprehensive Urban Hydrologic Modeling Handbook for Engineers and Planners.” 1st ed., MWH Soft Publ., Pasadena, CA, 376 pp.

Poku, S.E., and Arditi, D. (2006). "Construction scheduling and progress control using geographic information systems." Journal of Computing in Civil Engineering ASCE, 20(50), pp. 351-360.

Reitsma, R. F. (1996). "Structure and support of water-resources management and decision making." Journal of Hydrology, 177, pp. 253-268.

Reitsma, R. F. et al. (2005). "Decision support systems (DSS) for water resources management." In Water Resources Handbook, L. W. Mays editor, McGraw-Hill, New York, NY, pp. 33.1-33.35.

Rossman, L.A. (2005). "Stormwater Management Model Users Manual -Version 5." U.S. Environmental Protection Agency, National Risk Management Research Laboratory, Cincinnati, $\mathrm{OH}$.

Shamsi, U.M. (2002). "GIS Tools for Water, Wastewater, and Stormwater Systems." ASCE Press, Reston, VA, 273 pp. 
